\title{
PEMBELAJARAN TARI (TATAK) TINTOA SERSER MELALUI MEDIA AUDIO VISUAL UNTUK SISWA SMA SWASTA DAERAH SEI BEJANGKAR
}

\author{
LAILATUL FITRIA PANE \\ Prodi Pendidikan Tari
}

\begin{abstract}
This research was about learning cultural art esspecially dance art the topic was Tatak Tintoa Serser can be effective and efficient by using audio visual.In this research was using the theoriticals its relation with topic research about audio visual method and to result of theory practiced.This method was using descriptive quantitative. The population this method directly was the sample of SMA Swasta Daerah Sei Bejangkar. Tekhnik to collected data were research, library study, documentasi, and tes of practice.Based on the research, this research was using audio visual as a help tools to learnt who give result included psicimotoric value, the student was success $83,33 \%$ and the student was not success $16,66 \%$. The attitude of study result get the best value was $26,67 \%$, the student get better value was $40 \%$, and the student get anough value was $33,33 \%$. The kognitive of study result get the best value was $26,67 \%$, the student get better value was $40 \%$, and the student get anough value was $33,33 \%$. By using audio visual method of learning Tatak Tintoa Serser more effective and efficient.
\end{abstract}

Keyword: learning, audio visual, Tatak Tintoa Serser 
PENDAHULUAN

\begin{tabular}{lrr}
\multicolumn{2}{c}{ Pendidikan } & nasional \\
bertujuan untuk mencerdaskan & dan \\
kehidupan & bangsa & dia \\
mengembangkan manusia & Indonesia
\end{tabular}
seutuhnya, yaitu manusia yang beriman dan bertaqwa terhadap Tuhan Yang Maha Esa dan berbudi pekerti luhur, memiliki pengetahuan dan keterampilan, kesehatan jasmani dan rohani, kepribadian yang mantap dan mandiri serta rasa tanggung jawab kemasyarakatan dan kebangsaan. Pendidikan merupakan suatu proses pengalaman, karena kehidupan merupakan pertumbuhan, maka pendidikan berarti membantu pertumbuhan batin manusia tanpa dibatasi oleh usia. Berhasilatautidaknya proses pendidikansangatditentukanolehpem belajaran yang matang.

Mata pelajaran seni budaya di Sekolah Menengah Atas melingkupi beberapa mata pelajaran seni, diantaranya seni rupa, seni musik, seni teater, dan seni tari. Tujuan akhir dalam proses pembelajaran seni budaya khususnya seni tari adalah mampu berapresiasi dalam seni, mampu berekspresi dan berkreasi. Banyak manfaat yang diperoleh jika siswa mampu berkreasi dan berekspresi yaitu kreativitas siswa akan semakin berkembang. Dalam pembelajaran seni tari guru sering menemukan permasalahan dalam proses pembelajaran tari daerah yaitu kurangnya kemauan dan minat siswa dalam menarikan tari daerah dengan teknik-teknik yang benar.

Pembelajaran seni tari pada siswa Sekolah Menengah Atas tidak dapat maksimal dikarenakan pembelajaran seni budaya terbagi dengan pembelajaran yang lainnya meliputi seni rupa, seni musik, seni teater dan seni tari. Dalam kelas seni budaya, khususnya seni tari hanya memiliki waktu dua jam dalam seminggu. Sedangkan pembelajaran seni tari sangat membutuhkan waktu yang lebih banyak untuk melakukan suatu proses tari. Karena, dalam proses pembelajaran seni tari tidak hanya melalui teori saja, tetapi dalam pembelajaran seni tari juga membutuhkan waktu untuk praktek tari agar tercapainya tujuan 
pembelajaran. Selain itu ruang kelas juga tidak cukup memadai untuk terjadinya proses praktek tari, karena terbatasnya ruang gerak siswa dalam melakukan praktek tari.

SiswaSekolahMenengahAta smemilikidayaserap yang berbedabedakarena, tidak setiap siswa memiliki daya ingat yang baik. Dalam setiap kelasada siswa yang memiliki daya ingat baik dan ada pula yang memiliki daya ingat buruk.Jadi, sebagaiseorangpendidikkitadapatmen ggunakan media audio visual sebagaialatbantuuntukmempermudah siswadalammengingatsebuahpembela jarantari.

Dengancaramenggunakanpembelajar an media audio visual sangatlahmembantupendidikdalam proses belajarmengajarkarena, siswadapatmelihatlangsungtarian yang diajarkan.

Menurutsilabussenitarikelas

X SekolahMenengahAtas kurikulum 2013berdasarkanbentukpenyajianmat eritari yang akandiajarkanpadasiswaSekolahMen engahAtasadalahsalahsatumateritarid aerahsetempat yang dilakukanberpasangan/kelompok.

Salah

satumateritaridaerahsetempatadalah $T$ atakTintoaSerseryang

berasaldarietnis Sumatera Utara yaituetnisPakpak.TatakTintoaSersera dalahtariantentangmasyarakatPakpak dalambercocoktanam.TatakTintoaSer serinimenggambarkanpekerjaanpane npadiyaitumemisahkanbulir-

bulirpadidaritungkainya. Hal inidilakukandengancaramenginjakinjakpadi yang masihmelekatpadatungkainyadanpek erjaaninitidakdilakukansecarasendirit etapibersama-sama agar pekerjaanmemanenpadicepatselesai.

\section{LANDASAN TEORI}

Untuk

membahas pembelajaran Tatak Tintoa Serser melalui media audio visual untuk siswa SMA Swasta Daerah Sei Bejangkar, maka penulis menggunakan teorimedia audio visual dari Munadi sebagai teori utama dan juga teori penilaian praktek tari dari Arikunto. 


\section{Lokasi dan Waktu Penelitian}

Sesuai dengan judul

penelitian (Pembelajaran Tari (Tatak) Tintoa Serser Melalui Media

Audio Visual Untuk Siswa SMA Swasta Daerah Sei Bejangkar) makapenelitian dilaksanakan di SMA Swasta Daerah Sei Bejangkar. Waktu penelitian dilaksanakan pada awal bulan Januari hingga bulan Maret 2016.

\section{Populasi dan Sampel}

Populasi

Populasi dalam penelitian ini adalahkelas X SMA Swasta Daerah Sei Bejangkar, Kabupaten Batubara.

\section{Sampel}

Sampel dalam penelitian ini adalah satu kelas siswa kelas X SMA Swasta Daerah Sei Bejangkar, Kabupaten Batubara yang berjumlah 30 orang.

\section{Teknik Pengumpulan Data}

Teknik pengumpulan data yang dilakukan adalah sebagai berikut:

1. Pengamatan

2. Studi Kepustakaan
3. Dokumentasi

4. Tes

\section{Teknik Analisis Data}

Dalam penelitian ini data yang digunakan adalah analisis deskriptif kuantitatif dimana penelitian ini sesuai dengan fakta sosial dan memberi gambaran, keterangan serta uraian hasil penelitian.

\section{ISI}

Pembelajaran Tatak Tintoa Serser Melalui Media Audio Visual di SMA Swasta Daerah Sei Bejangkar

Pembelajaran Tatak Tintoa Serser melalui media audio visual untuk siswa SMA Swasta Daerah Sei Bejangkar pada pertemuan pertama, langkah awal yang dilakukan pada pembelajaran Tatak Tintoa Serser dengan menggunakan media audio visual guru memutarkan video Tatak Tintoa Serser agar siswa mengapresiasi video Tatak Tintoa Serser dan guru menjelaskan tentang bagaimana tari tersebut, serta menceritakan Tatak Tintoa Serser yang menggambarkan tentang 
bercocok tanam pada masyarakat Pakpak. Dalam kegiatan awal/pendahuluan siswa mengamati melalui media dan sumber belajar yaitu berupa video Tatak Tintoa Serser.

Dalam pembelajaran Tatak Tintoa Serser metode yang digunakan dalam pembelajaran ini adalah metode pembelajaran demonstrasi dengan alat bantu atau media belajarnya audio visualsebagai sumber belajar yang melibatkan indera pendengaran dan penglihatan. Siswa belajar dengan praktek terbimbing, tetap dalam bimbingan guru bidang studi Seni Budaya. Selain siswa belajar langsung melalui media audio visual, siswa tetap diarahkan atau dibimbing oleh guru bidang studi Seni Budaya agar tujuan pembelajaran tercapai dengan baik.

Kegiatan inti yang dilakukan dalam pembelajaran Tatak Tintoa Serser agar lebih efektif dilakukan dengan membagi siswa dalam beberapa kelompok belajar. Pemilihan kelompok dalam pembelajaran Tatak Tintoa Serser dibagi menjadi empat kelompok dari jumlah siswa tiga puluh orang, maka ada tiga kelompok yang berjumlah delapan orang dan satu kelompok yang berjumlah enam orang.

$$
\text { Pengelompokan dibagi }
$$

menurut kemampuan siswa, pada tiap-tiap kelompok siswa yang mampu dikelompokkan sebagaipemimpin atau leader. Agar dalam proses belajarnya terjadi pembelajaran tutor sebaya yang dibantu dengan media audio visual Tatak Tintoa Serser. Dengan menggunakan tutor sebaya dalam kelompok dapat membantu siswa yang kurang mampu memahami gerak-gerak tari yang ada di audio visual serta kurang mampu menghafal gerak dengan mudah. Dengan adanya tutor sebaya dalam setiap kelompok sehingga tidak ada kelompok yang terlihat sangat lemah dalam pembelajaran Tatak Tintoa Serser. Pada kegiatan inti ini siswa mengeksplorasi dan mencoba belajar tentang gerak-gerak dasar Tatak Tintoa Serser.

Dengan pembelajaran Tatak Tintoa Serser melalui media audio visual guru menggunakan fasilitas infocus dan VCD untuk menampilkan video pembelajaran 
Tatak Tintoa Serser pada saat proses pembelajaran berlangsung agar siswa dapat melihat dengan jelas gerak Tatak Tintoa Serser. Dengan menggunakanMedia pembelajaran melalui media audio visual guru tidak hanya menggunakan fasilitas infocus saja tetapi guru juga memberikan video berupa VCD yang telah disiapkan oleh penulis untuk diberikan kepada setiap kelompok agar siswa dapat mempraktekkan gerak Tatak Tintoa Serser tidak hanyadisekolah, namun siswa pun dapat latihan dirumah masingmasing dengan kelompok yang telah dibagikan. Sehingga dengan dilakukannya pembelajaran melalui media audio visual dapat membuat siswa lebih mudah dan cepat mempelajari setiap motif-motif gerak Tatak Tintoa Serser.

Pembelajaran tari melalui media audio visual merupakan solusi dari keterbatasan waktu belajar disekolah agar efektif dan efisien, mengingat pembelajaran tari disekolah hanya $2 \times 45$ menit dalam satu minggu dan pelajaran Seni Budaya juga terbagi menjadi empat bagian yaitu seni rupa, seni musik, seni teater dan seni tari, sehingga waktu yang diperlukan untuk praktek tari sangat terbatas. Dengan menggunakan media pembelajaran melalui media audio visual dapat mengatasi keterbatasan waktu belajar bidang studi seni budaya khususnya seni tari, karena siswa dapat belajar diluar sekolah seperti dirumah, karena adanya dibagikan video Tatak Tintoa Serser berupa VCD. Dalam bagian penutup, siswa dapat menyimpulkan dan menemukan kesulitan-kesulitan pada gerak Tatak Tintoa Serser

Pertemuan kedua, dalam pembelajaran Tatak Tintoa Serser siswa-siswi melanjutkan pembelajaran praktek tari seperti pada pertemuan sebelumnya. Siswasiswi mempraktekkan motif-motif gerak tari yang didapat pada pertemuan pertama dan yang telah dipelajari atau dipraktekkan dirumah secara berkelompok dengan menggunakan audio visual berupa VCD pembelajaran Tatak Tintoa Serser yang telah diberikan oleh penulis kepada masing-masing kelompok belajar. Dalam pertemuan ini guru melihat bagaimana cara 
kerja siswa dalam mempraktekan motif-motif gerak tari yang ada pada Tatak Tintoa Serser melalui media audio visual.

Pada pertemuan ketiga, guru Seni Budaya menilai belajar siswa yang telah berlangsung selama $2 \mathrm{x}$ pertemuan. Pertemuan ketiga ini guru mengambil penilaian belajar siswa secara berkelompok dengan aspek penilaian wiraga, wirama dan wirasa, serta sesuai dengan kriteria penilaian yang telah ditentukan. Pada pertemuan ketiga ini siswa akan dilihat bagaimana mereka belajar dengan menggunakan media audio visual. Penulis bertindak sebagai yang mengamati bagaimana penilaian belajar siswa melalui media audio visual dan dibimbing oleh guru. Disini penulis melihat bahwa dengan menggunakan media audio visual siswa lebih cepat dan mampu mempraktekkan gerak Tatak Tintoa Serser dengan teknik yang benar.

Dalam penelitian pembelajaran Tatak Tintoa Serser penulis hanya bertindak sebagai peneliti. Penulis bekerja sama atau berkolaborasi dengan guru bidang studi Seni Budaya. Dalam penelitian ini, guru seni budaya yang bertindak sebagai pengajar, penulis hanya memberikan dan memfasilitasi untuk pembelajaran Tatak Tintoa Serser seperti audio visual yang berisikan video Tatak Tintoa Serser. Penulis juga memberikan audio visual berupa VCD kepada masing-masing kelompok. Penulis bertindak sebagai yang mengamati belajar praktek tari siswa dalam pembelajaran Tatak Tintoa Serser melalui media audio visual. Guru menilai belajar siswa melalui aspek penilaian yaitu wiraga, wirama, dan wirasa. Penilaian belajar praktek Tatak Tintoa Serser dilakukan pada pertemuan ketiga.

\section{Penilaian Belajar Tatak Tintoa Serser}

Aspek penilaian yang telah ditentukan dalam penguasaan tari, indikator dalam aspek penilaian wiraga adalah teknik gerak kaki, teknik gerak tangan, teknik gerak badan, teknik gerak kepala, koordinasi gerak antar bagian dan hafalan gerak. Indikator dalam aspek penilaian wirama ialah dilihat dari kesesuaian gerak dengan iringan musik (tempo), sedangkan indikator 
dalam aspek penilaian wirasa ialah mimik dan penghayatan pada saat melakukan gerak Tatak Tintoa Serser. Pencapaian nilai wiraga sebesar 50\% karena wiraga adalah gerak dari bagian tubuh yang berarti gerak itu adalah yang paling utama dalam sebuah tarian. Sedangkan, pencapaian nilai wirama sebesar $30 \%$ penilaian wirama lebih rendah dari penilaian wiraga karena wirama adalah kesesuaian gerak antara musik iringan atau tempo apabila wiramanya sesuai maka akan mendapatkan nilai $30 \%$, pencapaian nilai wirama lebih sulit dibandingkan dengan pencapaian penilaian wirasa yang dilihat dari mimik serta penghayatan saat menari. Pencapaian nilai wirasa adalah $20 \%$.

Skor penilaian nilai penguasaan Tatak Tintoa Serser adalah $85-100=\mathrm{A}$ dengan nilai huruf "sangat baik" dan telah mencapai ketuntasan belajar, 75-84 = B dengan nilai huruf "baik" dan sudah mencapai ketuntasan belajar, 65-74= $\mathrm{C}$ dengan skor huruf "cukup" dengan nilai dibawah 70 siswa tidak mencapai nilai ketuntasan belajar, dan 55-64 =D dengan nilai huruf "kurang" dan siswa tidak mencapai ketuntasan belajar.

$$
\text { Hasil tes unjuk kerja }
$$

tersebut dianalisis dengan menggunakan perhitungan presentase. Jumlah siswa yang tuntas sebanyak 25 siswa dan jumlah siswa yang tidak tuntas sebanyak 5 siswa. Penilaian belajaar siswa dihitung dengan dengan kriteria penilaian ketuntasan belajar siswa. Siswa yang dikatakan mencapai ketuntasan belajar adalah siswa yang telah mencapai standart yang telah ditentukan yaitu siswa yang telah mendapatkan nilai antara 70 sampai dengan 100, sedangkan siswa yang tidak mencapai ketuntasan adalah siswa yang mendapatkan nilai dibawah 70. Rumus yang digunakan untuk menhitung ketuntasan belajar siswa adalah menurut pendapat Arikunto (2008).

$$
\begin{aligned}
\text { Ketuntasan Belajar } & =\frac{T}{T_{1}} \times 100 \% \\
& =\frac{2285}{3000} \times 100 \% \\
& =76,16 \%
\end{aligned}
$$

Untuk mengetahui hasil belajar siswa yang tuntas dan tidak tuntas adalah dengan rumus sebagai berikut: 
Ketuntasan Belajar $=$

$\frac{\text { jumla hsiswayangtuntas }}{\text { jumla hsiswa }} \times 100 \%$

$$
\begin{aligned}
& =\frac{25}{30} \times 100 \% \\
& =83,33 \%
\end{aligned}
$$

\section{Ketuntasan Belajar=}

jumla hsiswayangtidaktuntas

$$
\begin{aligned}
& \text { jumla hsiswa } \\
& =\frac{5}{30} \times 100 \% \\
& =16,66 \%
\end{aligned}
$$

Dari hasil di atas dapat disimpulkan bahwa nilai rata-rata siswa adalah $76,16 \%$, dan jumlah nilai siswa yang tuntas adalah $83,33 \%$, sedangkan jumlah nilai siswa yang tidak tuntas adalah 16,66\%. Dengan demikian penilaian belajar siswa SMA Swasta Daerah Sei Bejangkar dengan materi Tatak Tintoa Serser melalui media audio visual lebih efektif dan efisien, karena jumlah siswa yang tuntas 25 orang yang berarti lebih dari 50\% siswa yang tuntas dalam pembelajaran Tatak Tintoa Serser. Sedangkan jumlah siswa yang tidak tuntas hanya $16,66 \%$ yaitu berjumlah 5 orang siswa.

Penilaian belajar tidak hanya menggunakan penilaian psikomotorik (keterampilan) saja, tetapi juga menggunakan penilaian sikap siswa dalam melakukan gerak Tatak Tintoa Serser. Penilaian sikap dilakukan dengan aspek penilaian yaitu: (1) kerja sama, (2) tanggung jawab, (3) jujur, (4) disiplin. Kriteria penilaian sikap sebagai berikut: $1=$ Kurang, 2 = cukup, $3=$ baik, $4=$ sangat baik Jumlah nilai maksimal siswa adalah 16 dan jumlah nilai minimal siswa 4. Siswa yang mendapatkan nilai dengan jumlah 16 berarti siswa tersebut dikatakan mendapatkan nilai "sangat baik", siswa yang mendapatkan nilai dengan jumlah 12 berarti siswa tersebut dikatakan mendapatkan nilai "baik" sedangkan, siswa yang mendapatkan nilai dengan jumlah 8 siswa tersebut dikatakan mendapatkan nilai "cukup".

Penilaian sikap pada pembelajaran Tatak Tintoa Serser terlihat bahwa siswa yang mencapai nilai sangat baik berjumlah 8 orang siswa dengan presentase nilai $26,67 \%$, siswa yang mendapat nilai baik berjumlah 12 orang siswa dengan presentase nilai $40 \%$ dan siswa yang mendapatkan nilai cukup berjumlah 10 orang siswa dengan presentase nilai $33,33 \%$. 
Selain dengan penilaian psikomotorik dan penilaian afektif, tes penilaian belajar siswa juga dapat dilihat dari penilaian kognitif (pengetahuan) dapat dilihat bahwa penilaian kognitif (pengetahuan) siswa tentang materi Tatak Tintoa Serser adalah siswa yangmendapatkan nilai "sangat baik" berjumlah 8 orang dengan presentase nilai 26,67\%, siswa yang mendapatkan nilai "Baik" berjumlah 12 orang dengan presentase nilai $40 \%$, dan siswa yang mendapatkan nilai "Cukup" berjumlah 10 orang dengan presentase nilai 33,33\%.

Penilaian belajar siswa yang mendapatkan nilai sangat baik dan mencapai ketuntasan belajar pada tes psikomotorik (keterampilan) maka, dalam penilaian sikap siswa juga mendapatkan nilai sangat baik. Siswa yang mendapatkan nilai baik pada tes psikomotorik (keterampilan), pada penilaian sikap siswa juga mendapatkan nilai baik pada sikapnya dan pada penilaian pengetahuannya siswa juga mendapatkan nilai yang baik Sedangkan, siswa yang mendapatkan nilai cukup pada tes penilaian psikomotorik (keterampilan) maka, pada penilaian sikap dan penilaian pengetahuan siswa tersebut mendapatkan nilai yang cukup.

Penilaian belajar siswa dengan tes penilaian psikomotorik (keterampilan) seimbang dengan penilaian sikap siswa dan penilaian pengetahuan siswa, dengan penilaian psikomotorik dan penilaian afektif, tes penilaian belajar siswa juga dapat dilihat dari penilaian kognitif (pengetahuan) dapat dilihat bahwa penilaian kognitif (pengetahuan) siswa tentang materi Tatak Tintoa Serser adalah siswa yangmendapatkan nilai "sangat baik" berjumlah 8 orang dengan presentase nilai $26,67 \%$, siswa yang mendapatkan nilai "Baik" berjumlah 12 orang dengan presentase nilai $40 \%$, dan siswa yang mendapatkan nilai "Cukup" berjumlah 10 orang dengan presentase nilai 33,33\%.

\section{PENUTUP}

\section{Kesimpulan}

Berdasarkan penelitian yang dilakukan dalam penelitian Tatak Tintoa Serserini diperoleh kesimpulan, sebagai berikut: 
1. Penggunaan Media Audio Visual menjadikan pembelajaran seni budaya khususnya seni tari materi Tatak Tintoa Serser menjadi lebih efektif dan efisien.

2. Penilaian belajar siswa dengan tes psikomotorik nilai rata-rata siswa dengan penggunaan media pembelajaran audio visual memiliki nilai rata-rata sebesar 76,16 dan dapat disimpulkan secara umum bahwa melalui media audio visual dalam pembelajaran seni tari dengan materi Tatak Tintoa Serser belajar siswa menjadi lebih efektif dan efisien dengan jumlah siswa yang tuntas adalah 25 orang dan jumlah siswa yang tidak tuntas 5 orang.

3. Penilaian belajar siswa dengan tes penilaian afektif (sikap), siswa yang mencapai nilai sangat baik berjumlah 8 orang siswa dengan presentase nilai $26,67 \%$, siswa yang mendapat nilai baik berjumlah 12 orang siswa dengan presentase nilai $40 \%$ dan siswa yang mendapatkan nilai cukup berjumlah 10 orang siswa dengan presentase nilai $33,33 \%$.
4. Penilaian belajar siswa dengan tes penilaian kognitif (pengetahuan) siswa yang mencapai nilai "sangat baik" berjumlah 8 orang dengan presentase nilai $26,67 \%$, siswa yang mendapatkan nilai "Baik" berjumlah 12 orang dengan presentase nilai $40 \%$, dan siswa yang mendapatkan nilai "Cukup" berjumlah 10 orang dengan presentase nilai $33,33 \%$.

5. Dengan menggunakan media audio visual siswa mampu menari dengan teknik yang benar, menghafal setiap ragam gerak Tatak Tintoa Serser dengan cepat, mengkoordinasikan gerakan, menari dengan ketepatan tempo musik, menari dengan ekspresi, dan menari dengan keselarasan wiraga, wirama, dan wirasa.

\section{Saran}

Berdasarkan hasil penelitian dan kesimpulan, maka penulis menyampaikan beberapa saran antara lain:

1. Bagi guru yang menerapkan pembelajaran seni tari khususnya tarian daerah seperti Tatak Tintoa Serser, diharapkan 
hendaknya lebih teliti DAFTAR PUSTAKA

menentukan pemilihan media

pembelajaran, dan mampu

menggunakan cara atau strategi

lain dalam menyampaikan teori

maupun praktek, agar siswa

lebih tertarik dan bersemangat

dalam belajar dengan

penggunaan media audio visual.

2. Bagi penulis selanjutnya yang ingin melakukan penelitian yang serupa diharapkan penelitian ini dapat menjadi bahan perbandingan atau referensi yang bermanfaat untuk mendukung penelitian selanjutnya.

3. Pada penulisan selanjutnya disarankan untuk menggunakan media audio visual dalam meningkatkan hasil belajar siswa diluar Tatak Tintoa Serser pada pelajaran seni tari.

Darsono

Max. 2000.

BelajardanPembelajaran..Se marang: IKIP Semarang. Press

Hadi, Y, Sumandiyo. (2002). Kajian Tari, Yogyakarta: Pustaka Book Publisher.

Hamalik. 2004. Media Pembelajaran. Yogyakarta: BalaiPustaka

Koentjaraningrat.2000.Pengantar Ilmu Antropologi. Jakarta: Rineka Cipta

Kusumo.

Jati. 2011. PengaruhStrategiPembelajara n Peer TeachingTerhadapHasilBelaja rMenerapkanTeknikElektronik aAnalog dan Digital Dasar di SMK

DwitunggalTanjungMorawa.

Skripsi

K.Suzanne, Langer, 1977, Problems of Art, terjemahan F.X. Widyamanto, Bandung : Akademi Seni Tari Indonesia.

$\begin{array}{lr}\text { Kurath, Getrude } & \text { Prokosch. } \\ \text { "Panorama of } & \text { Dance } \\ \text { Ethnology",dalam } & \text { Jurnal } \\ \text { Current Anthropology I (1960), } \\ \text { 233-254 }\end{array}$


M. Jazuli, Soeryobrongto. 1987.

Kebudayaan. Bandung: STSI Press

Mulyasa, E. 2007.Kurikulum Tingkat SatuanPendidikan,

SebuahPaduanPraktis.

Bandung: RemajaRosdakarya

Munadi, Y. 2008. Media Pembelajaran. Jakarta: GaungPersada.

Nurwani. 2007. Pengetahuan Tari, Diktat Jurusan Sendratasik, FBS Universitas Negeri Medan.

Rahayu. 2012. Penerapan Model PembelajaranKooperatifTipe Learning Together TerhadapHasilBelajarSeniTar iPadaSiswa-siswiKelas VIII MTS Miftahussalam Medan TahunAjaran 2012/2013. Skripsi

Sanjaya, Wina. 2010. StrategiPembelajaranBerorien tasiStandar Proses Pendidikan. Jakarta: Kencana

Siregar, AmryBekker. 2014. Penerapan Media Pembelajaran Audio Visual UntukMeningkatkanKemampu anMenyanyikanLagulaguWajibNasionalPadaEkstr akulikulerSiswaKelas VIII-7 SMP Negeri 3 Sidikalang. Skripsi
Simanungkalit.Ribka Monika. 2011. PengaruhPenggunaan Media Audio Visual TerhadapHasilBelajarSejarah PerkembanganSeniLukisManc anegara di SMA Negeri 1 Kuala. Skripsi

Sihombing.EllyHasnah.2014. MeningkatkanHasilBelajarSen iTariMelalui Media Audio Visual (Materi Tor-Tor Hatasopisik) BagiSiswaKelas VII SMP Negeri 1 Bandar KhalifahTahunPelajaran 2013/2014.Skripsi

Soedarso,2006. Trilogi Seni. Penciptaan Eksistensi Dan Kegunaan Seni. ISI Yogyakarta

Soedarsono. 1976. Tari-tari Indonesia. Jakarta: Direktorat Jendral Kebudayaan.

Sudjana, N. 2001. Teori Pembelajaran. Bandung: Sinar Baru Algensindo.

Sugiyono. 2011. Metode Penelitian Kuantitatif, Kualitatif dan $R \& D$. Bandung:CV Afabeta

Susanto, Ahmad. 2013. TeoriBelajardanPembelajaran di SekolahDasar. Jakarta: KencanaPerdana Media Group. 
Sutikno, Sobry. 2014. Metode dan

Model-Model Pembelajaran.

Lombok:

Holistica.

Trianto.2009. Mendesain Model PembelajaranInovati-Progesif. Jakarta: Kencana
Purwanto. 2011. Evaluasi Hasil Belajar. Yogyakarta: Pustaka Pelajar.

Yamin, Martinis. 2003. Strategi

Pembelajaran Berbasis

Kompetensi. Jakarta:Balai

Pustaka.

http://www.seputarpengetahuan.com/ 2015/02/15-pengertian-pendidikanmenurut-para.html 